\title{
8
}

\section{imp parillm}

[Recensão a] Corteggiani, Jean-Pierre - Les Grandes Pyramides: chronique d'un mythe

Autor(es): $\quad$ Malheiro, Pedro de Abreu

Publicado por: Centro de História da Universidade de Lisboa

URL persistente:

URl:http://hdl.handle.net/10316.2/23938

DOI:

DOI:http://dx.doi.org/10.14195/0871-9527_18_25

Accessed : $\quad$ 26-Apr-2023 16:35:23

A navegação consulta e descarregamento dos títulos inseridos nas Bibliotecas Digitais UC Digitalis, UC Pombalina e UC Impactum, pressupõem a aceitação plena e sem reservas dos Termos e Condições de Uso destas Bibliotecas Digitais, disponíveis em https://digitalis.uc.pt/pt-pt/termos.

Conforme exposto nos referidos Termos e Condições de Uso, o descarregamento de títulos de acesso restrito requer uma licença válida de autorização devendo o utilizador aceder ao(s) documento(s) a partir de um endereço de IP da instituição detentora da supramencionada licença.

Ao utilizador é apenas permitido o descarregamento para uso pessoal, pelo que o emprego do(s) título(s) descarregado(s) para outro fim, designadamente comercial, carece de autorização do respetivo autor ou editor da obra.

Na medida em que todas as obras da UC Digitalis se encontram protegidas pelo Código do Direito de Autor e Direitos Conexos e demais legislação aplicável, toda a cópia, parcial ou total, deste documento, nos casos em que é legalmente admitida, deverá conter ou fazer-se acompanhar por este aviso.

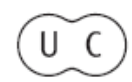



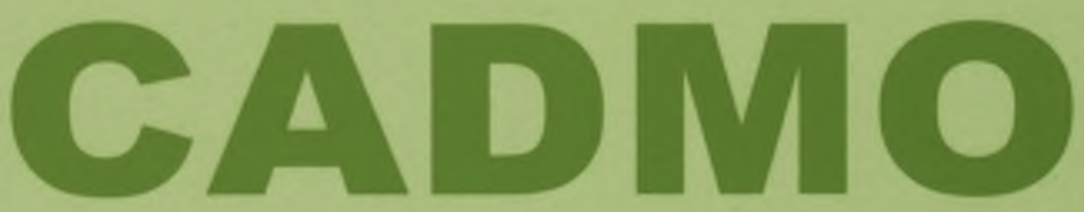

Revista de História Antiga

\author{
Centro de História \\ da Universidade de Lisboa
}

18

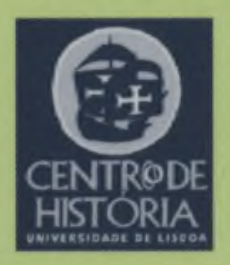

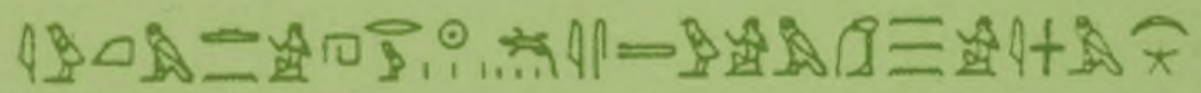

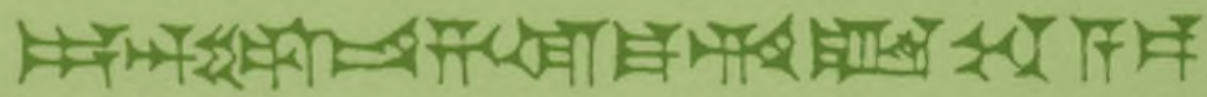

MHNIN AEI $\Delta$ E $\Theta E A ~ \Pi H \Lambda H I A \triangle E \Omega$ 
No derradeiro capítulo (X - «Rumo ao belo horizonte», pp. 341-356), Maruéjol examina o túmulo de Tutmés III, o $n^{\circ} 34$ do Vale dos Reis (KV 34). Depois de uma sóbria mas clarificadora "conclusão" (pp. 357-366), figura uma extensa bibliografia (pp. 369-442), além de uma resenha dos principais eventos da regência, co-regência e do reinado autónomo de Tutmés III (pp. 443-446), de uma lista das figuras inseridas no texto (pp. 447-450) e um profícuo índice (pp. 451-470).

Posto isto, Thoutmosis et la corégence avec Hatchepsout representa, a nosso ver, um notável e volumoso contributo para uma reabilitação histórica de um rei que a posteridade evocou, até à Época Greco-Romana, a sua brilhante memória. Aliando a erudição egiptológica a uma linguagem amena e acessível, a Autora apresenta factos e documentos submetidos a um rigoroso exame, passa em revista diversas teorias pré-existentes (arredando as que não assentam em fundamentos sólidos) e aventa, também, considerável número de hipóteses interpretativas escoradas em fontes coevas. Cabe, pois, felicitar F. Maruéjol pelo seu esforço na investigação e, obviamente, pelo mérito científico evidenciado no presente livro.

\section{Pedro de Abreu Malheiro}

JEAN-PIERRE CORTEGGIANI, Les Grandes Pyramides. Chronique d'un mythe, Paris: Gallimard, 2006, 127 páginas, com ilustrações a cores e a preto e branco. ISBN 2-07-033941-6

O Autor deste pequeno livro, um conceituado egiptólogo, é actualmente responsável pelos relatórios científicos e técnicos do conhecido Institut Français d'Archéologie Oriental (IFAO) do Cairo. Corteggiani já publicou numerosos artigos em revistas especializadas e, também, obras destinadas ao grande público (como L'Égypte des pharaons au Musée du Caire, L'Art de l'Egypte e Toutânkhamon, le Trésor).

Debrucemo-nos então sobre a obra Les Grandes Pyramides. Chronique d'un mythe: poderemos principiar por uma frase que o célebre Victor Hugo colocou na "boca" da pirâmide de Khufu, a única das Sete Maravilhas da Antiguidade que ainda se mantém de pé - «E eu - gritou Queops - sou a eternidade!". Com efeito, no planalto de Guiza, este monumento, bem como os de Khafré e Menkauré, colossais túmulos régios erigidos há mais de 4500 anos, não cessam de 
provocar admiração e fascínio em todos quantos os contemplam, afora conduzirem à formulação das especulações mais bizarras e mirabolantes sobre a identidade de quem mandou construir as pirâmides, a sua datação, o seu simbolismo e os métodos utilizados para a sua edificação. Nada disto causa estranheza se nos lembrarmos que, desde a Antiguidade e até à campanha de Bonaparte no Egipto, o altíssimo valor emblemático destes imponentes monumentos faraónicos se atesta em textos de autores clássicos, em lendas árabes e em relatos de viajantes ocidentais. A partir do século XIX foram ocorrendo sucessivas descobertas. Em torno das pirâmides vieram a achar-se complexos dedicados ao culto de cada um dos três soberanos da IV dinastia. No entanto, mesmo actualmente, elas parecem estar longe de terem revelado todos os seus segredos: o mistério da construção das mesmas continua a persistir e, não há muito, aventou-se a hipótese de existir uma câmara oculta na pirâmide de Khufu.

Ora é sobre tudo isto que o Autor discorre, numa linguagem objectiva e sucinta, confrontando os testemunhos de várias épocas com as verdades científicas e, transitando do mito para a realidade, relata a história ainda inacabada da redescoberta das paradigmáticas pirâmides de Guiza. Quanto às restantes da V dinastia e da VI, bem como as do Império Médio, só aflora alguns aspectos na derradeira secção do livro. Este está dividido em cinco capítulos: 1, "De Heródoto a Bonaparte" (pp. 10-27); 2, "Soldados, aventureiros e pioneiros» (onde se aborda a campanha de Napoleão de 1798, que marca o início da redescoberta do antigo Egipto, e as explorações de 1818 e 1837, pp. 28-45); 3, "O tempo da ciência» (que começa com a criação, em 1858, do Serviço das Antiguidades, e termina com as sucessivas campanhas arqueológicas no local de Guiza, desde finais de Oitocentos até às primeiras décadas do século XX, por $A$. Mariette, W. Flinders Petrie, G. Maspero, G. Reisner, etc., pp. 46-66); 4, «Imensos túmulos dominando outros túmulos» (pp. 66-83); e, 5, "Teses, hipóteses e realidades" (pp. 84-96). Por fim, consta um apêndice, rotulado "Testemunhos e documentos" (pp. 98-127), onde Corteggiani apresenta trechos alusivos às pirâmides de Guiza em escritos da Antiguidade Clássica, na literatura árabe, nas relações de viajantes ocidentais, além de uma breve crónica das grandes descobertas, uma cronologia das pirâmides e a bibliografia (não muito extensa).

Os capítulos 4 e 5 são, porventura, os mais dignos de interesse: no primeiro, o Autor desenvolve considerações sobre as pirâmides de Khufu, Khafré e Menkauré, que constituem um triplo complexo funerário. 
Descreve os elementos ligados aos túmulos reais (o templo alto, a calçada, o templo baixo) e também as mastabas de membros da família real e dos altos funcionários, na vasta necrópole de Guiza. No último, expõe um estado da questão das principais teorias elaboradas sobre as três pirâmides, mas principalmente centrando-se na de Khufu, objecto das mais diversas elucubrações (amiúde fantasiosas), desde J. Taylor, C. Piazzi Smith ou R. Proctor, no século XIX, até D. Davidson, E. Cayce, Spencer Lewis e, mais recentemente, A. Rutherford ou A. Pochan (que considerou que a Grande Pirâmide, além de ser um túmulo, também constituía um local isíaco de iniciação).

Quanto à problemática de como foram construídas as pirâmides, Corteggiani passa em revista as teorias mais significativas, salientando as de J.-P. e H. Houdin, que defendem ter sido aplicada uma rampa «interior», em espiral, partindo do nível da sexta camada do monumento piramidal, de M. Minguez, J. Davidovitz e J. Bertho. Os dois últimos, carreando argumentos semelhantes, sustentaram que a pirâmide de Khufu foi produzida com blocos de pedra «reconstituídos». Ante a maior parte destas hipóteses, o Autor mantém uma postura prudente, assinalando que a metodologia edificatória das pirâmides ainda levanta várias dúvidas e incertezas. Contudo, em relação às pesquisas do arquitecto G. Dormion sobre a eventual existência de uma câmara oculta no interior da Grande Pirâmide (teoria dissecada na obra La Chambre de Chéops, publicada em 2004, que comentámos noutro número da Cadmo), Corteggiani demonstra menos reservas e, tal como N. Grimal, aparenta aceitá-la. No entanto, para que se confirme a teoria, é preciso efectuar prospecções mais aprofundadas no interior do monumento de Khufu, mas as autoridades egípcias não estão nada inclinadas a autorizá-las. Além disso, resta sabermos se estamos perante a eventual descoberta do próprio sepulcro do soberano ou, se tal compartimento não consistirá apenas num espaço sem nada no seu interior.

Em suma, o presente livro revela-se profícuo sobretudo para todos aqueles que pretendam obter uma visão global e acessível das pirâmides de Guiza. Contudo, ao ser uma obra de carácter divulgativo, não substitui outras mais científicas, como as de J.-P. Lauer, I. E. S. Edwards, R. Stadelmann e M. Lehner, pelo que deverá constituir uma leitura de âmbito suplementar. 